\title{
Cumulative Effects of LDL Cholesterol and CRP Levels on Recurrent Stroke and TIA
}

\author{
Kazuo Kitagawa ${ }^{1}$, Naohisa Hosomi ${ }^{2}$, Yoji Nagai ${ }^{3}$,Tatsuo Kagimura ${ }^{4}$, Toshiho Ohtsuki ${ }^{5}$, Hirofumi Maruyama ${ }^{2}$, \\ Hideki Origasa ${ }^{6}$, Kazuo Minematsu ${ }^{7}$, Shinichiro Uchiyama ${ }^{8}$, Masakazu Nakamura ${ }^{7}$, Masayasu Matsumoto ${ }^{2,}$; \\ for the J-STARS collaborators
}

${ }^{1}$ Department of Neurology, Tokyo Women's Medical University, Tokyo, Japan

${ }^{2}$ Department of Clinical Neuroscience and Therapeutics, Hiroshima University Graduate School of Biomedical and Health Sciences, Hiroshima, Japan

${ }^{3}$ Clinical and Translational Research Center, Kobe University Hospital, Kobe, Japan

${ }^{4}$ Foundation for Biomedical Research and Innovation at Kobe, Translational Research Center for Medical Innovation, Kobe, Japan

${ }^{5}$ Stroke Center, Kindai University Hospital, Osakasayama, Japan

${ }^{6}$ Division of Biostatistics and Clinical Epidemiology, University of Toyama Graduate School of Medicine and Pharmaceutical Sciences, Toyama, Japan

${ }^{7}$ National Cerebral and Cardiovascular Center, Suita, Japan

${ }^{8}$ Clinical Research Center, International University of Health and Welfare, Center for Brain and Cerebral Vessels, Sanno Hospital and Medical Center, Tokyo, Japan

${ }^{9}$ Sakai City Medical Center, Sakai City Hospital Organization, Sakai, Japan

Aims: To investigate the relative contribution of on-treatment low-density lipoprotein (LDL) cholesterol and C-reactive protein (CRP) to the risk of recurrent stroke and transient ischemic attack (TIA) in patients with history of ischemic stroke.

Methods: A total of 1095 patients with non-cardioembolic ischemic stroke were randomized into two groups: control and patients receiving $10 \mathrm{mg}$ of pravastatin per day. After excluding 18 patients who did not have baseline CRP data, the effects of LDL cholesterol and CRP on recurrent stroke and TIA were prospectively assessed in 1077 patients.

Results: During the follow-up of $4.9 \pm 1.4$ years, there were 131 recurrent stroke or TIA cases. Patients with ontreatment $\mathrm{LDL}$ cholesterol $<120 \mathrm{mg} / \mathrm{dL}$ showed $29 \%$ reduction in recurrent stroke and TIA than those with LDL cholesterol $\geq 120 \mathrm{mg} / \mathrm{dL}$ (event rate 2.20 vs. 3.11 per 100 person-years, hazard ratio [HR] $0.71,95 \%$ confidence interval (CI) $0.50-0.99, p=0.048$ ). Patients with CRP $<1 \mathrm{mg} / \mathrm{L}$ had $32 \%$ reduction compared with that of patients with CRP $\geq 1 \mathrm{mg} / \mathrm{L}$ (event rate 2.26 vs. 3.40 per 100 person-years; HR $0.68,95 \%$ CI $0.48-0.96, p=$ 0.031). Although LDL cholesterol and CRP levels were not correlated in individual patients, those who achieved both $\mathrm{LDL}$ cholesterol $<120 \mathrm{mg} / \mathrm{dL}$ and CRP $<1 \mathrm{mg} / \mathrm{L}$ showed $51 \%$ reduction compared with that of patients with $\mathrm{LDL}$ cholesterol $\geq 120 \mathrm{mg} / \mathrm{dL}$ and CRP $\geq 1 \mathrm{mg} / \mathrm{L}$ (event rate 2.02 vs. 4.19 per 100 person-years; HR 0.49 , 95\% CI 0.31-0.79).

Conclusions: The control of both LDL cholesterol and CRP levels appears to be effective for preventing recurrent stroke and TIA in patients with non-cardiogenic ischemic stroke.

\section{See editorial vol. 26: 406-407}

Key words: Statin, Stroke prevention, Cholesterol, Crp, Inflammation

\section{Introduction}

The current guidelines for statin therapy recommend a specific goal for low-density lipoprotein (LDL) cholesterol to show clinical benefits ${ }^{1)}$. However, statin therapy also inhibits vessel inflammation, leading to risk reduction in cardiovascular events ${ }^{2}$. Statin is known to reduce the levels of the inflammatory bio- 
marker C-reactive protein (CRP) largely independent of LDL cholesterol ${ }^{3)}$. In the JUPITER trial, reduction in both LDL cholesterol and CRP levels was shown to have a cumulative effect in the primary prevention of cardiovascular events ${ }^{4}$. Although the JUPITER trial has set the cutoff of CRP as $2 \mathrm{mg} / \mathrm{L}$, the specific goal for CRP has not been determined in secondary stroke prevention.

The Japan Statin Treatment against recurrent stroke (J-STARS) examined the effect of pravastatin on stroke recurrence in patients with non-cardiogenic ischemic stroke. Although the rates of stroke and transient ischemic attack (TIA) were similar between the statin treatment group and control group, the incidence of atherothrombotic stroke was lower in the statin treatment group ${ }^{5)}$. As a sub-study of J-STARS, a high sensitivity (Hs)-CRP study randomized 1095 patients with recent non-cardioembolic ischemic stroke into two groups, control and treatment with 10 mg of pravastatin per day, and found a significant reduction in the CRP levels in the pravastatin treatment group ${ }^{6}$. The study also showed that patients that presented with CRP level $<1 \mathrm{mg} / \mathrm{L}$ during follow-up had a lower risk of recurrent stroke compared with that of patients with CRP level $\geq 1 \mathrm{mg} / \mathrm{L}^{6}$. Although reduction in LDL cholesterol levels certainly contributes to risk reduction in primary and secondary stroke ${ }^{7)}$, the benefit of lowering both LDL cholesterol and CRP levels after the start of statin therapy for preventing stroke recurrence remains unclear.

In the current American Heart Association/ American Stroke Association guidelines for the secondary prevention of stroke, statin therapy is strongly recommended for patients with ischemic stroke or TIA presumed to be of atherosclerotic origin and an $\mathrm{LDL}$ cholesterol level $\geq 100 \mathrm{mg} / \mathrm{dL}^{8)}$. However, according to the Japanese Atherosclerosis Society, the target of LDL cholesterol level is set at $<120 \mathrm{mg} / \mathrm{dL}$ for patients with a history of ischemic stroke ${ }^{9)}$. There is no consensus on the cutoff levels of CRP, but our recent study indicates that the ideal cutoff level should be $1 \mathrm{mg} / \mathrm{L}^{6}$.

In the present exploratory analysis of the J-STARS Hs-CRP data, we assessed the relative contributions of LDL cholesterol and CRP below the cutoff levels in recurrent stroke and TIA as primary outcome measure in J-STARS ${ }^{5)}$.

Our hypothesis is that management of both LDL cholesterol and CRP below the cutoff levels shows a cumulative effect on the prevention of recurrent stroke and TIA.

\section{Materials and Methods}

The study population of 1095 patients was derived from the J-STARS Hs-CRP sub-study ${ }^{6}$. The J-STARS Hs-CRP sub-study was approved by an ethical standards committee at each institution and registered with Government Clinical Trials NCT00361699. Briefly, patients between 45 and 80 years of age with a history of non-cardiogenic ischemic stroke within the preceding 1 month to 3 years were enrolled between March 2004 and February 2009. Patients who presented with total cholesterol between 180 and 240 $\mathrm{mg} / \mathrm{dL}$, without the use of statin, were enrolled. Major exclusion criteria included cerebral infarction of determined rare etiology, infarction associated with catheterization or surgery, and preferred use of statin for treating comorbid coronary artery disease. Patients were randomly assigned to the pravastatin treatment group $(n=545)$ and control group $(n=550)(1: 1$ allocation). After excluding 18 patients without baseline CRP data (9 in the pravastatin treatment group and 9 in the control group), 1077 patients, including 275 $(25.5 \%)$ with atherothrombotic infarction, 687 $(63.8 \%)$ with lacunar infarction, and 115 (10.7\%) with undetermined etiology, were included in this study (Fig. 1). The prespecified primary endpoint of stroke and TIA was used for all analyses in this study. Stroke was defined as focal clinical signs lasting $\geq 24 \mathrm{~h}$. The TIA condition was defined as an acute loss of focal cerebral or ocular function lasting $<24 \mathrm{~h}$.

To assess the effect of LDL cholesterol and CRP on event rates, LDL cholesterol and CRP levels were obtained at randomization, after 2 and 6 months postrandomization, and at 2 and 5 years post-randomization or at study completion.

Blood CRP levels were measured in the Special Reference Laboratory, Inc. (Tokyo, Japan) as highsensitivity CRP.

\section{Statistical Analysis}

For on-treatment LDL cholesterol and CRP levels, the mean level for LDL cholesterol and median level for CRP was employed at multiple time points. We planned to measure CRP levels five times during the entire follow-up period; however, due to occurrence of primary events, death, withdrawal of consent,

Address for correspondence: Kazuo Kitagawa, Department of Neurology, Tokyo Women's Medical University, 8-1 Kawada-cho, Shinjuku-ku, Tokyo 162-8666, Japan E-mail: kitagawa.kazuo@twmu.ac.jp

Received: July 11, 2018 Accepted for publication: August 21, 2018

Copyright@2019 Japan Atherosclerosis Society

This article is distributed under the terms of the latest version of CC BY-NC-SA defined by the Creative Commons Attribution License. 


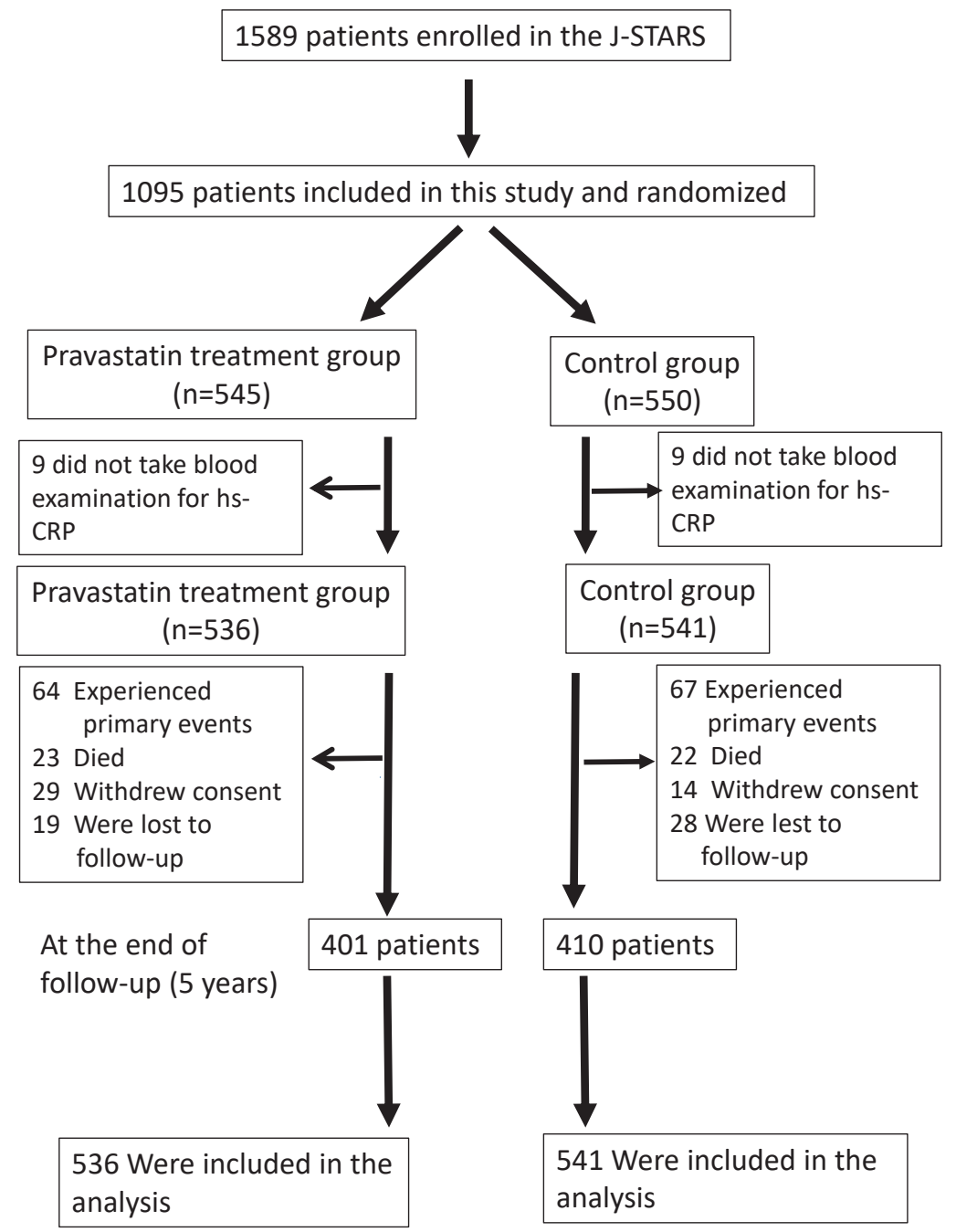

Fig. 1. Trial profile

follow-up loss, and refusal for blood test, the number of patients with CRP measurements taken once, twice, three times, four times, and five times were 50, 67, 189, 294, and 477, respectively. The data were analyzed with intention-to-treat (ITT) analysis. The patients were first divided into two groups based on whether the mean LDL cholesterol level during the follow-up period until the occurrence of stroke and TIA events was either $\geq 120 \mathrm{mg} / \mathrm{dL}$ or less than this value. Although an LDL cholesterol concentration cutoff of $100 \mathrm{mg} / \mathrm{dL}$ is internationally recommended $^{8)}$, the LDL cholesterol cutoff of $120 \mathrm{mg} / \mathrm{dL}$ is recommended by the Japanese Atherosclerosis Society ${ }^{9)}$. Our patients were also divided into two groups based on whether the median CRP level during the follow-up period until the occurrence of stroke and TIA events was either $\geq 1 \mathrm{mg} / \mathrm{L}$ or less than this value. To address the cumulative effect of the achieved CRP levels across the strata of achieved LDL cholesterol levels, the 1077 patients were further divided into four groups based on the LDL cholesterol concentration cutoff of $120 \mathrm{mg} / \mathrm{dL}$ and CRP cutoff of $1 \mathrm{mg} / \mathrm{L}$. The incidence rate and the $95 \%$ confidence interval (CI) were estimated in the groups. The cumulative incidence rates of recurrent stroke and TIA events were estimated by the Kaplan-Meier method. In order to adjust the potential effect of randomization, the HR was estimated using proportional hazards regression models with frailty models clustered by stroke subtypes, high blood pressure, diabetes, and statin use and adjusted by age, sex, body mass index, total cholesterol, HDL cholesterol, triglyceride, hypertension, fasting blood glucose, chronic kidney disease, creatinine, and smoking as covariates.

\section{Results}

During the follow-up of $4.9 \pm 1.4$ years, there 
Table 1. Baseline characteristics in reference to on-treatment level of LDL cholesterol and Hs-CRP

\begin{tabular}{|c|c|c|c|c|c|c|}
\hline Characteristic & \multicolumn{2}{|c|}{ LDL cholesterol } & $P$ value & \multicolumn{2}{|c|}{ CRP } & $P$ value \\
\hline Age, years & $66.8 \pm 8.5$ & $65.7 \pm 8.4$ & 0.040 & $66.0 \pm 8.6$ & $67.0 \pm 8.1$ & 0.084 \\
\hline Male, $N(\%)$ & $416(70.4)$ & $323(66.5)$ & 0.188 & $474(64.8)$ & $265(76.8)$ & $<.0001$ \\
\hline BMI, $\mathrm{kg} / \mathrm{m}^{2}$ & $23.60 \pm 3.10$ & $23.82 \pm 2.92$ & 0.241 & $23.48 \pm 3.01$ & $24.15 \pm 3.00$ & 0.001 \\
\hline Total cholesterol, mg/dl & $202.0 \pm 23.1$ & $219.4 \pm 24.4$ & $<.0001$ & $210.0 \pm 24.9$ & $209.5 \pm 26.0$ & 0.743 \\
\hline HDL cholesterol, mg/dl & $55.2 \pm 17.7$ & $50.3 \pm 11.8$ & $<.0001$ & $54.9 \pm 16.2$ & $48.9 \pm 12.9$ & $<.0001$ \\
\hline Triglyceride, mg/dl & $141.5 \pm 83.4$ & $145.3 \pm 68.9$ & 0.417 & $134.7 \pm 67.7$ & $161.3 \pm 91.6$ & $<.0001$ \\
\hline Hypertension, $N(\%)$ & $458(77.5)$ & $367(75.5)$ & 0.489 & $543(74.2)$ & $282(81.7)$ & 0.008 \\
\hline Coronary artery disease, $N(\%)$ & $29(4.9)$ & $25(5.1)$ & 0.968 & $37(5.1)$ & $17(4.9)$ & 1.000 \\
\hline Chronic kidney disease, $N(\%)$ & $150(25.4)$ & $116(23.9)$ & 0.616 & $165(22.5)$ & $101(29.3)$ & 0.021 \\
\hline Creatinine, $\mathrm{mg} / \mathrm{dl}$ & $0.806 \pm 0.202$ & $0.800 \pm 0.219$ & 0.631 & $0.784 \pm 0.198$ & $0.844 \pm 0.228$ & $<.0001$ \\
\hline Smoker, $N(\%)$ & $326(55.2)$ & $251(51.6)$ & 0.270 & $355(48.5)$ & $222(64.3)$ & $<.0001$ \\
\hline Use of antiplatelet agents, $N(\%)$ & $545(92.2)$ & $440(90.5)$ & 0.383 & $674(92.1)$ & $311(90.1)$ & 0.347 \\
\hline Use of statin, $N(\%)$ & $388(65.7)$ & $148(30.5)$ & $<.0001$ & $375(51.2)$ & $161(46.7)$ & 0.183 \\
\hline \multicolumn{7}{|l|}{ Ischemic stroke subtype } \\
\hline Atherothrombotic infarction, $N(\%)$ & $154(26.1)$ & $121(24.9)$ & 0.507 & $181(24.7)$ & $94(27.2)$ & 0.215 \\
\hline Lacunar infarction, $N(\%)$ & $369(62.4)$ & $318(65.4)$ & & $479(65.4)$ & $208(60.3)$ & \\
\hline Undetermined etiology, $N(\%)$ & $68(11.5)$ & $47(9.7)$ & & $72(9.8)$ & $43(12.5)$ & \\
\hline
\end{tabular}

The categorical data are compared by chi-square test and the numerical data are compared by non-paired $t$-test, and Wilcoxon two-sample test for Hs-CRP. TIA: transient ischemic attack, BMI: body mass index, HDL: high density lipoprotein, LDL: low density lipoprotein, Hs-CRP: high-sensitivity $\mathrm{C}$ reactive protein, IQR: interquartile range

were 131 cases of recurrent stroke or TIA. The primary outcomes included 22 atherothrombotic infarctions, 54 lacunar infarcts, 5 cardioembolic infarctions, 26 infarcts of other etiology or unclassified infarctions, 10 intracerebral hemorrhages, 1 subarachnoid hemorrhage, and 13 TIAs. The rate of the primary outcomes was similar between the pravastatin treatment group $(2.59 \% / 100$ person-years) and the control group (2.60\%/100 person-years) (HR 1.01; 95\% CI 0.72 $1.43, P=0.947)$. In this post-hoc study of the J-STARS Hs-CRP sub-study, 536 patients were assigned to the pravastatin treatment group. Among 536 patients, $438(81.7 \%)$ had taken pravastatin until the onset of primary outcome (recurrent stroke and TIA), death, or the end of follow-up. In contrast, 82 of 541 patients $(15.2 \%)$ in the control group started taking statin during the study period according to the judgment of the primary care doctor due to increased LDL cholesterol levels, comorbidity of coronary artery disease, or peripheral vascular disease. The patient characteristics regarding on-treatment LDL cholesterol and CRP levels are shown in Table 1. Both baseline and on-treatment CRP levels were similar between patients with on-treatment LDL cholesterol $\geq 120$ $\mathrm{mg} / \mathrm{dL}$ and those with LDL cholesterol $<120 \mathrm{mg} / \mathrm{dL}$. Furthermore, there was no relationship between the LDL cholesterol and CRP levels at baseline and on treatment, and changes in the LDL cholesterol level were not associated with changes in the CRP level after statin treatment in the statin group (Fig. 2). 

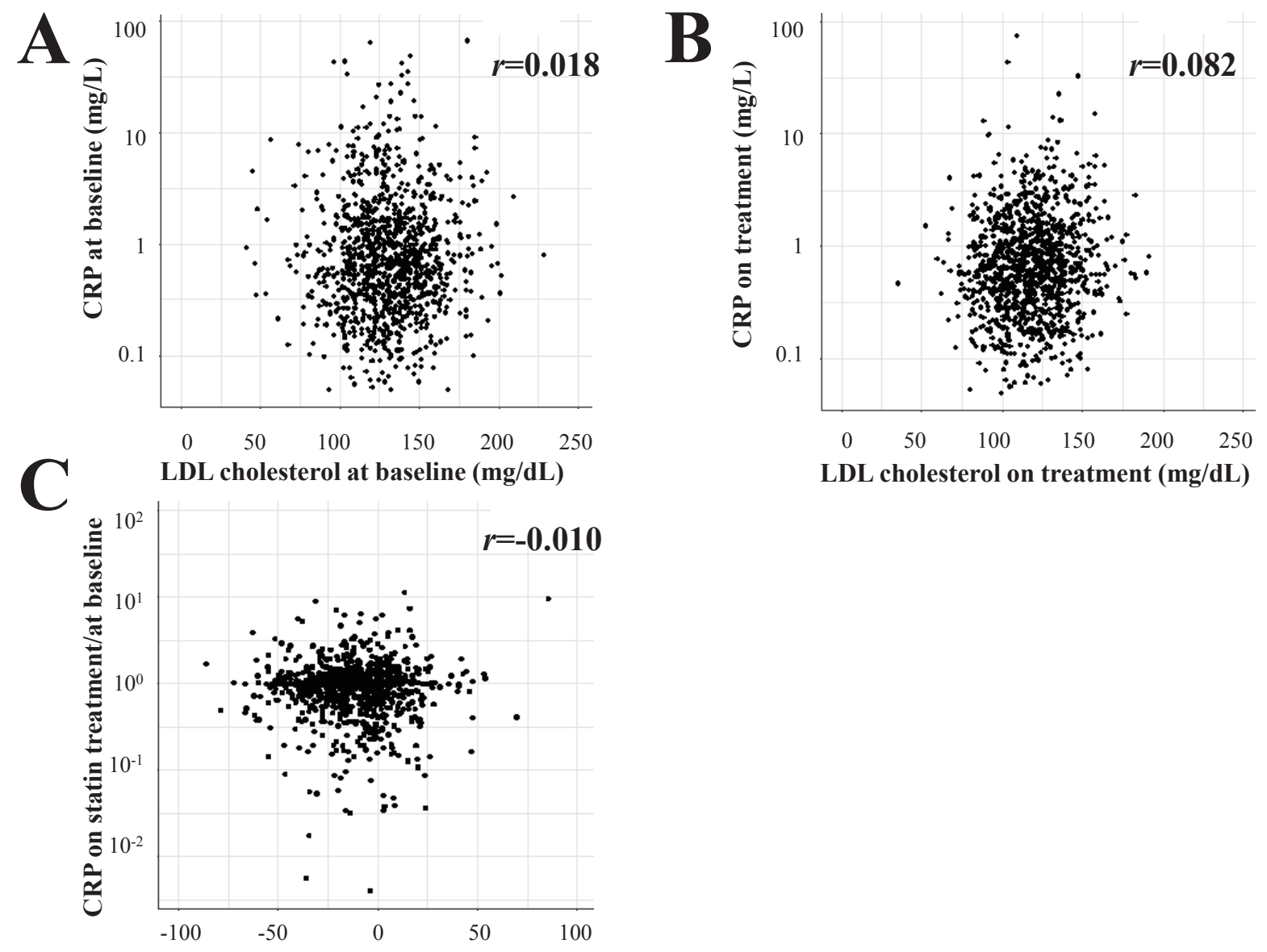

Difference of LDL cholesterol between baseline and on statin treatment $(\mathrm{mg} / \mathrm{dL})$

Fig. 2. Relationship between LDL cholesterol and CRP levels at baseline and on treatment, and relationship between changes in the CRP and LDL cholesterol levels after treatment in the statin group
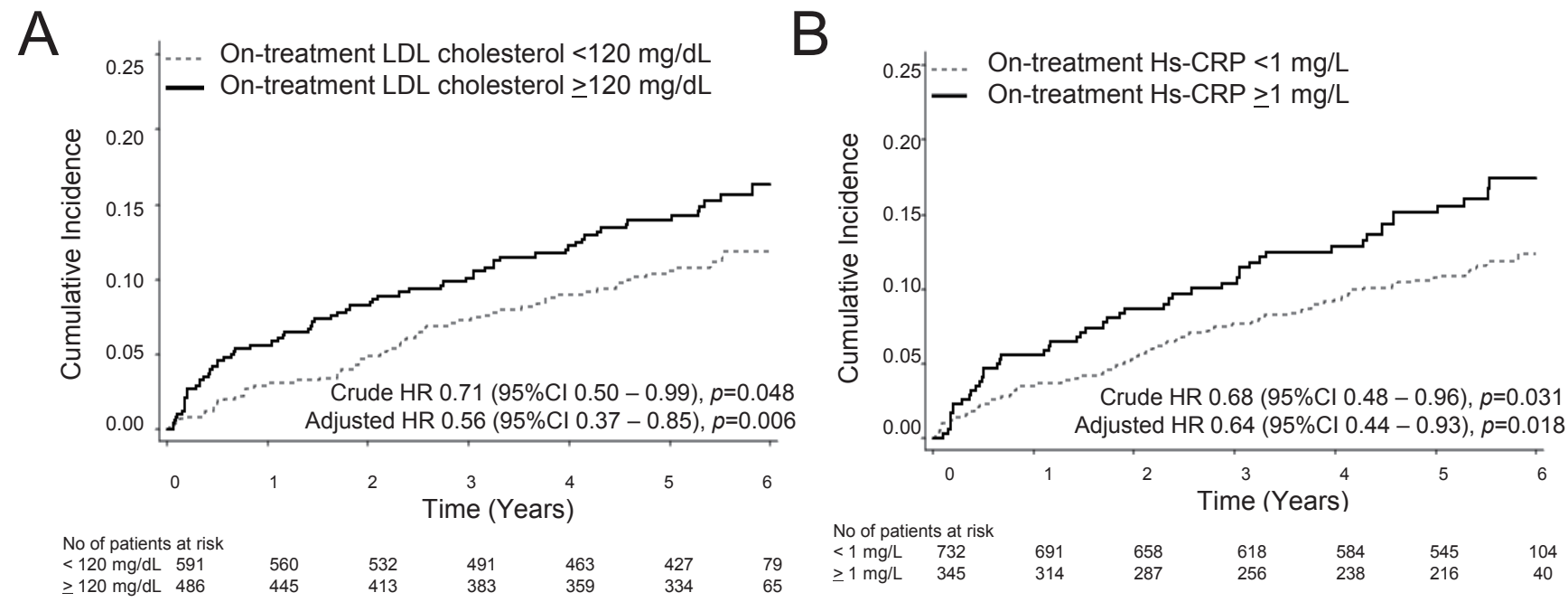

Fig. 3.

(A) The cumulative incidence of recurrent stroke and TIA according to on-treatment LDL cholesterol levels (above or below $100 \mathrm{mg} / \mathrm{dL}$ ). (B)

The cumulative incidence of recurrent stroke and TIA according to on-treatment LDL cholesterol levels (above or below $120 \mathrm{mg} / \mathrm{dL}$ ). (C)

The cumulative incidence of recurrent stroke and TIA according to on-treatment CRP levels (above or below $1 \mathrm{mg} / \mathrm{L}$ ). 

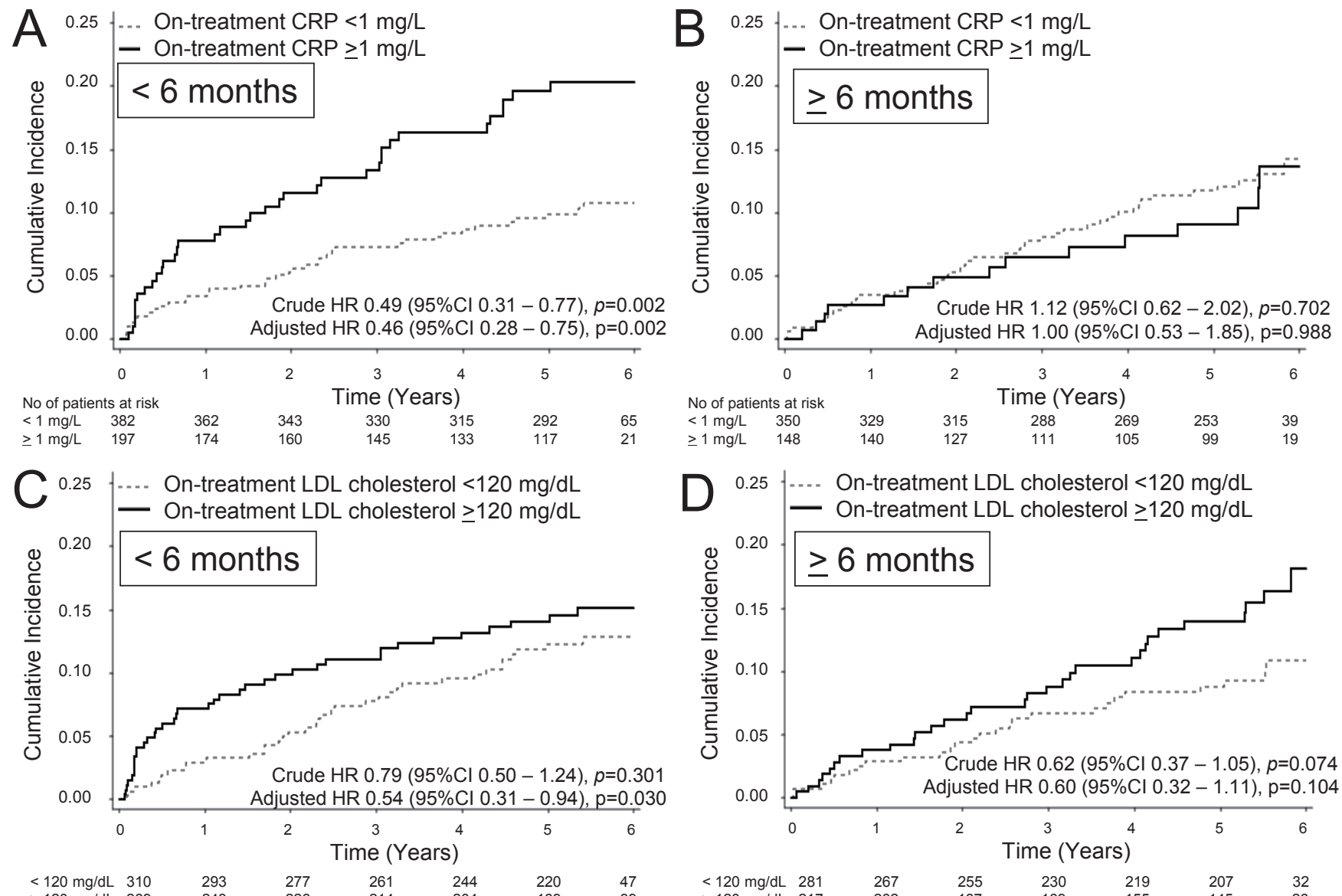

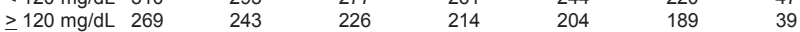

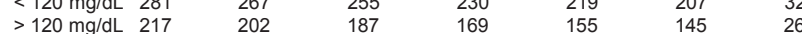

Fig. 4.

(A, C) Patients enrolled within 6 months after index stroke (early cohort): (B, D) Patients enrolled after 6 months since index stroke (late cohort). (A, B) The cumulative incidence of recurrent stroke and TIA according to on-treatment CRP levels (above or below $1 \mathrm{mg} / \mathrm{L})$. (C, D) The cumulative incidence of recurrent stroke and TIA according to on-treatment LDL cholesterol levels (above or below $120 \mathrm{mg} / \mathrm{dL}$ ).

Patients with on-treatment LDL cholesterol < $120 \mathrm{mg} / \mathrm{dL}(n=591)$ showed an annual incidence of recurrent stroke or TIA of $2.20 / 100$ person-years, demonstrating significant risk reduction compared with that of patients with LDL cholesterol $\geq 120 \mathrm{mg} /$ $\mathrm{dL}(n=486)(3.11 / 100$ person-years) (HR 0.71; $95 \%$ CI $0.50-0.99, p=0.048$, adjusted HR 0.56 ; $95 \%$ CI $0.37-0.85, p=0.006$ ) (Fig. 3A). Patients with ontreatment CRP $<1 \mathrm{mg} / \mathrm{L}$ showed an annual incidence of recurrent stroke or TIA of 2.26/100 person-years, demonstrating 32\% reduction compared with that of patients with CRP $\geq 1 \mathrm{mg} / \mathrm{L}(3.40 / 100$ person-years) (HR 0.68; 95\% CI 0.48-0.96, $p=0.031$, adjusted HR $0.64 ; 95 \%$ CI $0.44-0.93, p=0.018$ ) (Fig. 3B). The effect of CRP on recurrent events was evident in patients enrolled within 6 months after stroke. When patients were divided into two groups, early and late cohorts at enrollment, before $(N=579)$ and after $(N=498) 6$ months since index stroke, the effect of
$\mathrm{CRP} \geq 1 \mathrm{mg} / \mathrm{L}$ was very evident in patients enrolled within 6 months after index stroke. In these patients, those with $\mathrm{CRP}<1 \mathrm{mg} / \mathrm{L}$ showed an annual incidence of recurrent stroke and TIA of 2.02/100 personyears, demonstrating robust reduction compared with that of patients with CRP $\geq 1 \mathrm{mg} / \mathrm{L}(4.30 / 100$ person-years) (HR 0.49; 95\% CI 0.31-0.77, $p=0.002$, adjusted HR $0.46 ; 95 \%$ CI $0.28-0.75, p=0.002$ ) (Fig. 4A). In 498 patients enrolled after 6 months of index stroke, the annual incidence of recurrent stroke and TIA was similar between patients with CRP $<1$ $\mathrm{mg} / \mathrm{L}(2.53 / 100$ person-years) and those with CRP $\geq$ $1 \mathrm{mg} / \mathrm{L}(2.26 / 100$ person-years) (HR $1.12 ; 95 \% \mathrm{CI}$ $0.62-2.02, p=0.702$, adjusted HR $1.00 ; 95 \%$ CI $0.53-1.85, p=0.988$ ) (Fig. 4B). However, the effect of LDL cholesterol on recurrent events was not significant in both cohorts. In the early cohort, patients with LDL cholesterol $<120 \mathrm{mg} / \mathrm{dL}(N=310)$ showed an annual incidence of recurrent stroke and TIA of 
Table 2. Combined effect of on-treatment control below the cut-off level of LDL cholesterol and CRP on recurrent stroke and TIA

\begin{tabular}{|c|c|c|c|c|c|c|c|c|}
\hline Group & $N$ & $\begin{array}{c}\text { Incidence } \\
\text { Rate } \\
\text { (100 persons } \\
\text { /year) }\end{array}$ & $\begin{array}{c}\text { Crude } \\
\text { HR } \\
(95 \% \mathrm{CI})\end{array}$ & $P$ value & $\begin{array}{l}\text { Overall } \\
P \text { value }\end{array}$ & $\begin{array}{c}\text { Adjusted } \\
\text { HR }\end{array}$ & $p$ value & $\begin{array}{l}\text { Overall } \\
p \text { value }\end{array}$ \\
\hline $\mathrm{LDL}$ cholesterol $\geq 120 \mathrm{mg} / \mathrm{dL}, \mathrm{CRP} \geq 1 \mathrm{mg} / \mathrm{L}$ & 171 & 4.19 & 1 & & 0.032 & 1 & & 0.019 \\
\hline LDL cholesterol $<120 \mathrm{mg} / \mathrm{dL}, \mathrm{CRP} \geq 1 \mathrm{mg} / \mathrm{L}$ & 174 & 2.67 & $\begin{array}{c}0.64 \\
(0.37,1.12)\end{array}$ & 0.118 & & $\begin{array}{c}0.51 \\
(0.23,1.14)\end{array}$ & 0.099 & \\
\hline LDL cholesterol $<120 \mathrm{mg} / \mathrm{dL}, \mathrm{CRP}<1 \mathrm{mg} / \mathrm{L}$ & 417 & 2.02 & $\begin{array}{c}0.49 \\
(0.31,0.79)\end{array}$ & 0.003 & & $\begin{array}{c}0.41 \\
(0.22,0.78\end{array}$ & 0.006 & \\
\hline Interaction with LDL cholesterol and CRP & & & & 0.601 & & & 0.51 & \\
\hline
\end{tabular}

Hazard ration (HR) was expressed using the LDL cholesterol $\geq 120 \mathrm{mg} / \mathrm{dL}$ and CRP $\geq 1 \mathrm{mg} / \mathrm{L}$ as the reference group. HR was estimated using proportional hazards regression models with frailty models clustered by stroke subtypes, high blood pressure, diabetes and statin use, and adjusted by age, sex, BMI, TC, HDL-C, TG, hypertension, FBS, chronic kidney disease creatinine and smoking as covariate. LDL: low density lipoprotein, CRP: C-reactive protein, CI: confidence interval.

2.43/100 person-years, similar to that of patients with LDL cholesterol $\geq 120 \mathrm{mg} / \mathrm{dL}(N=269)(3.08 / 100$ person-years) (HR 0.79 ; $95 \%$ CI $0.50-1.24, p=$ 0.301 , adjusted HR $0.54 ; 95 \%$ CI $0.31-0.94, p=$ 0.030) (Fig. 4C). In the late cohort, the annual incidence of recurrent stroke and TIA was also similar between patients with LDL cholesterol $<120 \mathrm{mg} / \mathrm{dL}$ $(N=281)(1.95 / 100$ person-years $)$ and those with LDL cholesterol $\geq 120 \mathrm{mg} / \mathrm{dL}(N=217)(3.14 / 100$ person-years) (HR 0.62 ; $95 \%$ CI $0.37-1.05, p=$ 0.074 , adjusted HR 0.60; 95\% CI $0.32-1.11, p=$ 0.104) (Fig. 4D).

The annual incidence of recurrent stroke or TIA was 4.19/100 person-years in the group who achieved neither target (LDL cholesterol $\geq 120 \mathrm{mg} / \mathrm{dL}, \mathrm{CRP} \geq$ $1 \mathrm{mg} / \mathrm{L}), 2.67 / 100$ person-years in the group who achieved only LDL cholesterol (LDL cholesterol < $120 \mathrm{mg} / \mathrm{dL}, \mathrm{CRP} \geq 1 \mathrm{mg} / \mathrm{L}), 2.59 / 100$ person-years in the group who achieved only CRP (LDL cholesterol $\geq 120 \mathrm{mg} / \mathrm{dL}, \mathrm{CRP}<1 \mathrm{mg} / \mathrm{L}$ ), and 2.02/100 person-years in the group who achieved both targets (LDL cholesterol $<120 \mathrm{mg} / \mathrm{dL}$, CRP $<1 \mathrm{mg} / \mathrm{L}$ ) (Table 2, Fig. 5). Compared with the group who did not achieve either target (LDL cholesterol $\geq 120 \mathrm{mg}$ / $\mathrm{dL}, \mathrm{CRP} \geq 1 \mathrm{mg} / \mathrm{L}$ ), all other three groups showed risk reduction in recurrent stroke or TIA, but control of both LDL cholesterol $(<120 \mathrm{mg} / \mathrm{dL})$ and CRP $(<$ $1 \mathrm{mg} / \mathrm{L})$ had a cumulative effect on reducing stroke or TIA, with achievement of levels below the cutoff value in either or both factors $(p=0.032)$. However, the cumulative effect of LDL cholesterol and CRP on recurrent stroke and TIA events did not imply a synergy effect because the interaction with LDL cholesterol and CRP was not significant $(p=0.601)$ (Table 2).

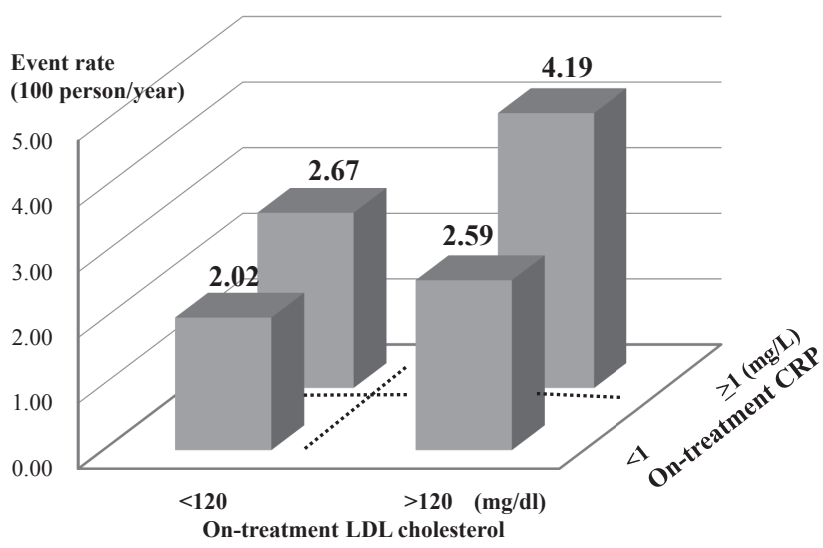

Fig. 5.

Annual event rate in four groups according to on-treatment levels of LDL cholesterol (above or below $120 \mathrm{mg} / \mathrm{dL}$ ) and CRP (above or below $1 \mathrm{mg} / \mathrm{L}$ ).

\section{Discussion}

The most important finding in this study is that the on-treatment levels of both LDL cholesterol and Hs-CRP below the cutoff value showed a cumulative effect on the risk reduction of recurrent stroke or TIA. This finding is in-line with that of the JUPITER trial for primary prevention ${ }^{10)}$. Physicians should be recommended to evaluate both LDL cholesterol and CRP levels when treating patients with a history of ischemic stroke.

We first set the cutoff levels of LDL cholesterol at $120 \mathrm{mg} / \mathrm{dL}$ according to the Japanese Atherosclerosis Society ${ }^{9)}$. The American Heart Association/American Stroke Association guidelines for the secondary 
prevention of stroke indicate a target of LDL cholesterol level $<100 \mathrm{mg} / \mathrm{dL}$ for patients with a history of ischemic stroke ${ }^{8)}$. However, the number of patients with LDL cholesterol level $<100 \mathrm{mg} / \mathrm{dL}$ was only 231 among the 1077 patients because the guidelines of the Japanese Atherosclerosis Society recommends the target of LDL cholesterol level $<120 \mathrm{mg} / \mathrm{dL}^{9)}$. Our results showed that the control of LDL cholesterol level $<120 \mathrm{mg} / \mathrm{dL}$ could prevent recurrent stroke and TIA (Fig. 3), suggesting the validity of this cutoff level. However, the beneficial effect of LDL cholesterol $<100 \mathrm{mg} / \mathrm{dL}$ was not examined in this study due to the small sample size. In the SPARCL trial, patients with LDL cholesterol $<70 \mathrm{mg} / \mathrm{dL}$ had a $28 \%$ reduction, although those with LDL cholesterol between 70 and $100 \mathrm{mg} / \mathrm{dL}$ had no significant risk reduction ${ }^{11)}$. Because on-treatment LDL cholesterol levels in the pravastatin group was approximately 100 $\mathrm{mg} / \mathrm{dL}$ and not many patients achieved LDL cholesterol $<100 \mathrm{mg} / \mathrm{dL}$ in this study, future studies are needed to clarify whether intense LDL control $<70$ $\mathrm{mg} / \mathrm{dL}$ would be more beneficial than management at $<120 \mathrm{mg} / \mathrm{dL}$ in the Asian population.

We set the cutoff level of CRP at $1 \mathrm{mg} / \mathrm{L}$, which is lower than that in Western countries ${ }^{12)}$. The CRP levels differ among different ethnic populations, with lower levels occurring in the Asian population than in Western countries ${ }^{13}$, 14). In Japan, the CRP level in the general healthy population is approximately $0.5 \mathrm{mg} /$ $\mathrm{L}^{13)}$, but the cutoff value as a vascular risk factor remains undetermined. In the J-STARS Hs-CRP substudy, patients with a recent history of ischemic stroke had a significantly higher risk of recurrent stroke and vascular events when the on-treatment CRP level was $\geq 1 \mathrm{mg} / \mathrm{L}^{6}$. Therefore, we employed $1 \mathrm{mg} / \mathrm{L}$ as the cutoff value of CRP. However, Li et al. showed that in the acute stage of ischemic stroke, patients with CRP $>3 \mathrm{mg} / \mathrm{L}$ had an increased risk of recurrent stroke compared with that of patients with CRP $<1 \mathrm{mg} / \mathrm{L}$ within 90 days ${ }^{15)}$. The cutoff value in the Asian population still requires further research. Our results showed that the CRP value was more related to recurrent stroke (Fig. 4A, 4B) in patients within 6 months since index stroke than in those enrolled after 6 months. The level of vessel inflammation as suggested by elevated CRP levels might be more related to recurrent stroke in the early period since index stroke.

In the JUPITER trial, in the patient group with LDL cholesterol $<70 \mathrm{mg} / \mathrm{dL}$, the control of CRP level $<2 \mathrm{mg} / \mathrm{L}$ or even $<1 \mathrm{mg} / \mathrm{L}$ had a cumulative protective effect on the primary prevention of cardiovascular events ${ }^{10)}$. In the IMPROVE-IT trial, the addition of ezetimibe to simvastatin treatment for patients stabilized after acute coronary syndrome increased the number of patients who met dual LDL cholesterol and CRP targets, and the patients achieving dual targets had lower vascular events than that of patients meeting neither targets, suggesting the importance of residual inflammatory risk ${ }^{16}$. Anti-inflammatory therapy itself can be effective in preventing recurrent cardiovascular events because treatment with antiinterleukin- $1 \beta$ antibody was recently shown to reduce the CRP levels and prevent vascular events independent of lipid-level lowering ${ }^{17)}$. In addition, further LDL cholesterol reduction beyond the maximal statin therapy can be achieved with proprotein convertase subtilisin/kexin type-9 (PCSK9) inhibition ${ }^{18)}$. In Further Cardiovascular Outcomes Research with PCSK9 Inhibition in Subjects with Elevated Risk (FOURIER), aggressive LDL lowering to $30 \mathrm{mg} / \mathrm{dL}$ with Evolocumab was shown to reduce cardiovascular events, including stroke ${ }^{18)}$. The role of CRP under such LDL cholesterol levels remains unclear.

This study has several limitations. First, the LDL cholesterol level was defined in the inclusion criteria in this study, whereas the CRP level was not included. Thus, the CRP levels widely differed at baseline, possibly weakening the effect of CRP level on the event. Second, pravastatin was employed as statin therapy; thus, the lowering effects on LDL cholesterol and CRP were modest, possibly weakening the effect of statin treatment on stroke recurrence. Third, CRP measurements were not repeated at baseline; thus, we included 31 patients (2.9\% of total patients) with elevated CRP levels $(>10 \mathrm{mg} / \mathrm{L})$ at baseline in order to avoid selection bias. Fourth, the sample size and event number were limited; thus, we could not analyze the cumulative effects of LDL cholesterol and CRP levels on each stroke subtype such as large artery atherosclerosis and lacunar stroke. Lastly, this study included only Japanese patients with history of ischemic stroke. Therefore, the cumulative effect of LDL cholesterol and CRP levels on recurrent stroke needs to be evaluated in the white and black race.

In conclusion, our study suggests a cumulative effect of LDL cholesterol and CRP on recurrent stroke and TIA in patients with ischemic stroke. Physicians should be recommended to evaluate both LDL cholesterol and CRP levels for better medical management with statin in patients with a history of ischemic stroke.

\section{Acknowledgements}

The authors thank all study participants, physicians, supporting medical staff, and co-workers for their assistance in the preparation and execution of this study. 


\section{Sources of Funding}

This study was supported initially by a grant from the Ministry of Health, Labor, and Welfare of Japan. After the governmental support expired, the study was conducted in collaboration with Hiroshima University Graduate School of Biomedical and Health Sciences and the Foundation for Biomedical Research and Innovation. The latter organization receives unconditional research grants from several pharmaceutical companies, including Daiichi Sankyo Co., Ltd., which is commercializing pravastatin. However, the company was not involved in the design and execution of this study.

\section{Conflicts of Interest}

KK serves on the speakers' bureau of Takeda Pharmaceutical Company Limited, Nippon Boehringer Ingelheim Co., Ltd., Daiichi Sankyo Company, Limited, MSD K.K., Mitsubishi Tanabe Pharma Corporation, Shionogi \& Co., Ltd., Sumitomo Dainippon Pharma Co., Ltd., Astellas Pharma Inc., Kyowa Hakko Kirin Co., Ltd., Otsuka Pharmaceutical Co., Ltd., Sanofi K.K., Shionogi Inc., Pfizer Inc., BristolMyers Squibb Company, Bayer Yakuhin, Ltd., received research grant from Grants-in-Aid for Scientific Research (15H04844), Takeda Pharmaceutical Company Limited, Nippon Boehringer Ingelheim Co., Ltd., Daiichi Sankyo Company, Limited, MSD K.K., Sumitomo Dainippon Pharma Co., Ltd., Astellas Pharma Inc., AstraZeneca K.K., Kyowa Hakko Kirin Co., Ltd., Otsuka Pharmaceutical Co., Ltd., Sanofi K.K., Eisai Co., Ltd, Pfizer Inc., and Bayer Yakuhin, Ltd. NH serves on the speakers' bureau of Mochida Phamaceutical Co., Ltd. HM received research grant from Daiichi Sankyo Company, Eisai Co., Ltd, Pfizer Inc., Takeda Pharmaceutical Company Limited, Otsuka Inc., Nihon Pharmaceutical, Shionogi, Teijin Pharma, Fuji Film, Nippon Boehringer Ingelheim Co., Ltd., Limited, Nihon MediPhysics, Bayer Yakuhin, Ltd., MSD K.K., Kyowa Hakko Kirin Co., Ltd., Novartis, Mitsubishi Tanabe Pharma. KM serves on the speakers' bureau of Otsuka Pharmaceutical Co., Ltd., Bayer Yakuhin,. SU serves on the speakers' bureau of Boehringer Ingelheim, Bristol-Myers Squibb, and Bayer Yakuhin MM serves on the speakers' bureau of Takeda Pharmaceutical Company Limited, Nippon Boehringer Ingelheim Co., Ltd., Daiichi Sankyo Company, Limited, MSD K.K., Sumitomo Dainippon Pharma Co., Ltd., Otsuka Pharmaceutical Co., Ltd., Sanofi K.K., Bristol-Myers Squibb Company, Bayer Yakuhin, Ltd., Novartis Pharma K.K., received research grant from Daiichi
Sankyo Company, Eisai Co., Ltd, Pfizer Inc., Takeda Pharmaceutical Company Limited, Otsuka Inc., Nihon Pharmaceutical, Nippon Boehringer Ingelheim Co., Ltd., Limited, Nihon Medi-Physics, Bayer Yakuhin, Ltd., MSD K.K., Mitsubishi- Tanabe Pharma, Shionogi IncOther authors had no conflicts of interest.

\section{References}

1) Stone NJ, Robinson JG, Lichtenstein AH, Bairey Merz CN, Blum CB, Eckel RH, Goldberg AC, Gordon D, Levy D, Lloyd-Jones DM, McBride P, Schwartz JS, Shero ST, Smith SC Jr, Watson K, Wilson PW, Eddleman KM, Jarrett NM, LaBresh K, Nevo L, Wnek J, Anderson JL, Halperin JL, Albert NM, Bozkurt B, Brindis RG, Curtis LH, DeMets D, Hochman JS, Kovacs RJ, Ohman EM, Pressler SJ, Sellke FW, Shen WK, Smith SC Jr, Tomaselli GF. 2013 ACC/AHA guideline on the treatment of blood cholesterol to reduce atherosclerotic cardiovascular risk in adults: a report of the American College of Cardiology/ American Heart Association Task Force on Practice Guidelines. Circulation, 2014; 129 (25 Suppl 2): S1-45

2) Ridker PM. From C-reactive protein to Interleukin-6 to Interleukin-1: Moving Upstream to Identify Novel Targets for Atheroprotection. Circ Res, 2016; 118: 145-156

3) Albert MA, Danielson E, Rifai N, Ridker PM. Effect of statin therapy on C-reactive protein levels: the pravastatin inflammation/CRP evaluation (PRINCE): a randomized trial and cohort study. JAMA, 2001; 286: 64-70

4) Ridker PM, Danielson E, Fonseca FA, Genest J, Gotto AM Jr, Kastelein JJ, Koenig W, Libby P, Lorenzatti AJ, MacFadyen JG, Nordestgaard BG, Shepherd J, Willerson JT, Glynn RJ; JUPITER Study Group. Rosuvastatin to prevent vascular events in men and women with elevated C-reactive protein. N Engl J Med, 2008; 359: 2195-2207

5) Hosomi N, Nagai Y, Kohriyama T, Ohtsuki T, Aoki S, Nezu T, Maruyama H, Sunami N, Yokota C, Kitagawa K, Terayama Y, Takagi M, Ibayashi S, Nakamura M, Origasa H, Fukushima M, Mori E, Minematsu K, Uchiyama S, Shinohara Y, Yamaguchi T, Matsumoto M; J-STARS Collaborators. A Multicenter, Randomized, Open-label, Parallel-group Study. EBioMedicine, 2015; 2: 1071-1078

6) Kitagawa K, Hosomi N, Nagai Y, Kagimura T, Ohtsuki T, Origasa H, Minematsu K, Uchiyama S, Nakamura M, Matsumoto M; J-STARS Investigators. Reduction in High-Sensitivity C-Reactive Protein Levels in Patients with Ischemic Stroke by Statin Treatment: Hs-CRP SubStudy in J-STARS. J Atheroscler Thromb, 2017; 24: 1039-1047

7) Amarenco P, Labreuche J. Lipid management in the prevention of stroke: review and updated meta-analysis of statins for stroke prevention. Lancet Neurol, 2009; 8: 453-463

8) Kernan WN, Ovbiagele B, Black HR, Bravata DM, Chimowitz MI, Ezekowitz MD, Fang MC, Fisher M, Furie KL, Heck DV, Johnston SC, Kasner SE, Kittner SJ, Mitchell PH, Rich MW, Richardson D, Schwamm LH, Wilson JA; American Heart Association Stroke Council, Council on Cardiovascular and Stroke Nursing, Council 
on Clinical Cardiology, and Council on Peripheral Vascular Disease. Guidelines for the prevention of stroke in patients with stroke and transient ischemic attack: a guideline for healthcare professionals from the American Heart Association/American Stroke Association. Stroke, 2014; 45: 2160-2236

9) Teramoto T, Sasaki J, Ishibashi S, Birou S, Daida H, Dohi $S$, Egusa G, Hiro T, Hirobe $K$, Iida M, Kihara S, Kinoshita M, Maruyama C, Ohta T, Okamura T, Yamashita S, Yokode M, Yokote K; Japan Atherosclerosis Society Committee for Epidemiology and Clinical Management of Atherosclerosis. Diagnosis of atherosclerosis. Executive Summary of the Japan Atherosclerosis Society (JAS) Guidelines for the Diagnosis and Prevention of Atherosclerotic Cardiovascular Diseases in Japan - 2012 Version. J Atheroscler Thromb, 2014; 21: 296-298

10) Ridker PM, Danielson E, Fonseca FA, Genest J, Gotto AM Jr, Kastelein JJ, Koenig W, Libby P, Lorenzatti AJ, Macfadyen JG, Nordestgaard BG, Shepherd J, Willerson JT, Glynn RJ; JUPITER Trial Study Group. Reduction in C-reactive protein and LDL cholesterol and cardiovascular event rates after initiation of rosuvastatin: a prospective study of the JUPITER trial. Lancet, 2009; 373: 11751182

11) Amarenco P, Goldstein LB, Szarek M, Sillesen $H$, Rudolph AE, Callahan A 3rd, Hennerici M, Simunovic L, Zivin JA, Welch KM; SPARCL Investigators. Effects of intense low-density lipoprotein cholesterol reduction in patients with stroke or transient ischemic attack: the Stroke Prevention by Aggressive Reduction in Cholesterol Levels (SPARCL) trial. Stroke, 2007; 38: 3198-3204

12) Meschia JF, Bushnell C, Boden-Albala B, Braun LT, Bravata DM, Chaturvedi S, Creager MA, Eckel RH, Elkind MS, Fornage M, Goldstein LB, Greenberg SM, Horvath SE, Iadecola C, Jauch EC, Moore WS, Wilson JA; American Heart Association Stroke Council; Council on Cardiovascular and Stroke Nursing; Council on Clinical Cardiology; Council on Functional Genomics and Translational Biology; Council on Hypertension. Guidelines for the primary prevention of stroke: a statement for healthcare professionals from the American Heart Association/
American Stroke Association. Stroke, 2014; 45: $3754-$ 3832

13) Arima H, Kubo M, Yonemoto K, Doi Y, Ninomiya T, Tanizaki Y, Hata J, Matsumura K, Iida M, Kiyohara Y. High-sensitivity C-reactive protein and coronary heart disease in a general population of Japanese: the Hisayama study. Arterioscler Thromb Vasc Biol, 2008; 28: 13851391

14) Ridker PM, Buring JE, Shih J, Matias M, Hennekens $\mathrm{CH}$. Prospective study of C-reactive protein and the risk of future cardiovascular events among apparently healthy women. Circulation, 1998; 98: 731-733

15) Li J, Zhao X, Meng X, Lin J, Liu L, Wang C, Wang A, Wang Y, Wang Y; CHANCE Investigators. High-Sensitive C-Reactive Protein Predicts Recurrent Stroke and Poor Functional Outcome: Subanalysis of the Clopidogrel in High-Risk Patients With Acute Nondisabling Cerebrovascular Events Trial. Stroke, 2016; 47: 2025-2030

16) Bohula EA, Giugliano RP, Cannon CP, Zhou J, Murphy SA, White JA, Tershakovec AM, Blazing MA, Braunwald E. Achievement of dual low-density lipoprotein cholesterol and high-sensitivity C-reactive protein targets more frequent with the addition of ezetimibe to simvastatin and associated with better outcomes in IMPROVE-IT. Circulation, 2015; 132: 1224-1233

17) Ridker PM, Everett BM, Thuren T, MacFadyen JG, Chang WH, Ballantyne C, Fonseca F, Nicolau J, Koenig W, Anker SD, Kastelein JJP, Cornel JH, Pais P, Pella D, Genest J, Cifkova R, Lorenzatti A, Forster T, Kobalava Z, Vida-Simiti L, Flather M, Shimokawa H, Ogawa H, Dellborg M, Rossi PRF, Troquay RPT, Libby P, Glynn RJ; CANTOS Trial Group. Antiinflammatory Therapy with Canakinumab for Atherosclerotic Disease. N Engl J Med, 2017; 377: 1119-1131

18) Sabatine MS, Giugliano RP, Keech AC, Honarpour N, Wiviott SD, Murphy SA, Kuder JF, Wang H, Liu T, Wasserman SM, Sever PS, Pedersen TR; FOURIER Steering Committee and Investigators. Evolocumab and Clinical Outcomes in Patients with Cardiovascular Disease. N Engl J Med, 2017; 376: 1713-1722 